\title{
The Unconscious Construction of Film Intension with Understanding Deviation
}

\author{
Gao Shuai \\ School of Mechanical \& Vehicle Engineering, Linyi University, Linyi, China \\ E-mail: gaoshuai@lyu.edu.cn
}

Key words: Chinese film, Cultural discount, Orientalism, Cultural hegemony.

\begin{abstract}
Film, a kind of cultural symbol, which contains a lot of ideology and cultural connotation, has become an important carrier of cultural transmission, but the Western world owns understanding bias of China's film connotation, which results in the trade deficit of Chinese film. From the perspective of shallow analysis, cultural differences led to the film products can not be fully understood and absorbed by the Western world. From the deep-seated analysis, the cultural discount is formed by the generated biased line of eastern ideal in the understanding western process. The ultimate goal is to construct cultural hegemony and cultural imperialism of western world, these three are inseparable.
\end{abstract}

\section{Introduction}

Since the birth of the film, it is given the meaning of cultural carrier and cultural symbols. Throughout the Chinese film releases the situation in the United States, the Chinese film market is not optimistic. Hindering the development of Chinese owns many reasons, such as cultural discounts, orientalism and cultural hegemony, which are the most representative of the three ideological roots.

\section{The Discussion about the Shallow Theory of Film Understanding Bias - Cultural Discount}

In the preface to "culture and imperialism", Said emphasizes on the importance of culture. Culture has become a stage, a variety of political, ideological forces make the competition in this stage. Culture is not a quiet territory, it can even become a battlefield and all kinds of strength appear and compete with each other [1]. The status of cultural competition is prominent and the corresponding significance of cultural products have been constantly reconstructed, the US national ideology with Hollywood movies covering all over the world, accounted for $70 \%$ of the global market share. The United States of democracy, race, heroism and other concepts penetrate into other countries, while the Chinese film has not been successfully penetrated into other countries, so it did not perform to disseminate the function of Chinese culture.

The reason for this is that the cultural discount is the shallow theoretical source of the film trade deficit. The cultural discount is a neutral word, and this concept was raised in 1988 by Hoskins and Mulhouse. The two pointed out that the differences in cultural backgrounds and the degree of cultural awareness lead to the consumption of cultural content of the product. However, this can not be understood and absorbed by other regions of the audience, and even be intensively rejected, so that the value of cultural products greatly reduced, especially Movies and novel texts themselves have unique cultural awareness and cultural discourse of cultural products [2]. Indeed, it is easy to understand and learn for the people who are familiar with the culture. However, those who are unfamiliar with the other culture, the attraction will be reduced and the audience's interest and understanding will be compromised.

Cultural structure differences are the main reasons for the existing of cultural discounts, which is also the main reason for the Chinese film which is unable to get out. China and the United States are completely affected by different cultures and civilizations. China is attached to "Chinese culture" or 
"Confucian culture", and Europe and the United States are influenced by the "Christian" civilization. These two thinking and ideology are completely different, so Europe and the United States viewers can not understand the Chinese film owning some incredible movements. At the same time, due to a specific cultural background, the domestic audience has the same cultural background, values, beliefs, history and culture, social system, thinking and there is no big difference, so some cultural symbols will be positively interpretationed, the film will be popular and appreciated in the domestic market. If the film placed in Europe and the United States, the understanding bias may be appeared.

\section{The Discussion about the Deep Thinking of Film Misreading - Orientalism}

Taking Zhang Yimou film as an example, Chinese film has also a success story. By virtue of "Red Sorghum", Zhang Yimou has successfully entered into the International Film Festival in 1987, and also Chinese film came into the national market. Then "JuDou" "Raise the Red Lantern" and several other films are also internationally acclaimed. "Red Sorghum" film shows a love and hate between a love, hate and bloody men with a courageous woman. "Red lanterns hanging high" using a symbolic approach, created a mysterious mystery for the West: the film can be wives and wives in groups, and the way of the expression is also vague, lanterns pick up the meaning of the hero will go into a lady's boudoir. These elements have been regarded as China's unique folklore on the international stage, but some film critics call it "pseudo-folk", "pseudo-folk" judgment based on the origin of Orientalism theory. With the development of the film, more and more "Oriental elements" such as martial arts, martial arts, Chinese medicine, opera, shadow play, Red Guards, Mao Zedong, violence were incorporated into the film. Some elements are no stranger to the West, they may exist in the "Marco Polo Travels" "Arabian Nights". From the perspective of the Western world, other supernatural, distant fairy tale and strange, incredible story seems to be full of temptations. In fact, it is only mixed with a large number of Western imagination in the Eastern color, just coincides with the oriental symbolic performance.

Cultural discounts are abstract summary of shallow performance, and the root of cultural discounts is the main content of our discussion. In order to achieve their own cultural interests, the West began to develop a gesture, form some ideas, and use a means of operation to understand, describe, construct and use some relevant ideas, which also have an impact on their people and even the eastern people, this is the direct reason for the construction of orientalism [3]. Chen Kaige "Farewell My Concubine" and "Butterfly King" both are the same type of subject matter, much are also be welcomed by overseas visitors. If we study in depth, we will be surprised to find that these films have similar cultural elements, coinciding with the West for the East's imagination. In the understanding of the East, in "Farewell My Concubine", "Yu Ji" for "Overlord" romance is metamorphosis, abnormal, depressed and is not understood. But in the eyes of the West, this is normal for the East, as Matteo Ricci to Orientalism perspective,it explains the "Chinese people are homosexual", the Western understanding of the East and the understanding of the East are very different [3]. Oriental women are gentle, obedient to men, they are selfless and pure. The ending of "Farewell My Concubine" and "Butterfly Monarch" is striking resemblance, the male heroes are dressed as their liking female role, commit suicide to die. This end is in line with the Orientalism, the Western fantasy for the Oriental women.

From the East to the Orientalism and cultural imperialism, Edward disclosed the Western conspiracy theory and formed a complete set of theoretical discourse on the East. Orientalism is put forward mainly for academic research, but its influence gradually began to penetrate into the drama, music, film and other cultural products. Orientalism is not Europe's purely fabricated, but material content accumulated in the process of Western understanding of the East, which has formed a set of theoretical support system. "The accumulation of this material level makes Orientalism, which is an oriental-related knowledge system, as a universally accepted filtering framework in which the East enters into the Western consciousness through this framework, just as the same material accumulation makes it from Eastern. The concept of the continent spread into the general culture and 
continue to generate new ideas from it [4]. The existence of orientalism began to make the Western perception change in the facts of the East, expression and experience. The West produce a self-serving oriental philosophy through colonial filtration. In the beginning of the "Oriental Studies", Said alley pointed out that Orientalism has three connotations: one is as an "Oriental" discipline academic research, the second is a way of thinking about distinction between "Oriental" and " The West " in the ontological and epistemological sense, the third is a mechanism to control, rebuild and Junlin Oriental [4]. The interpretation of the third connotation is the core issue of Orientalism.

"Orientalism" is a prejudice and factional theme, the word itself has a derogatory color. Orientalism about conquesting the film and television broadcasting, became the dream of Chinese film. Orientalism's initial goal is to point to Islam, Islamic ideology is supported by Islam, is very different with the West supporting with Christianity. China is automatically planned to the Eastern field and did not escape this robbery. Oriental with a long history and great civilization has a great attraction due to their mysterious and seductive in the West. In order to highlight its own civilization, the West hinted their progress and vicissitude, and began to dream of one of its own oriental: "hard to understand, exotic, pornographic, where it is the home of the mysterious story, cruel and brutal. All this is covered in an old, mysterious tradition. Orientalism is not the original product of the East and is the imagination of the West to show the Western fiction of a" other "image, is the East Exaggerated, especially on the backward, decadent, ignorant of exaggeration. In the book "Orientalism", Said was defined as "an expression system envisioned by a set of forces that brought the East into Western academic and Western consciousness, and later Western empires in". Orientalism on the oriental mind, genealogy and atmosphere, put forward an explanation, was treated as a fixed phenomenon. Because of the influence of orientalism, the West thinks that China is backward, brutal, ancient, and also imagined that China is a cruel, mercenary, dependent on the land, indulge in pleasures, opium, wives and tribes. It is because of these imagination, when the film appears to marry the concubine scene, martial arts cold weapon duel, oriental women chaste attention to the scene, the Western all the fantasy of the East have been confirmed, they think this is the real East. The narrow oriental doctrine makes them immersed in the Western fantasy for the East, and they think that the East is weak and should be attached to the West. This concept unconsciously and unconsciously affected the audience for the film and other cultural products, the choice of the West for the East to really understand. In the postmodern context, orientalism continues its traditional role, distorting irony and suppressing Asian civilization in the ideological sense, and the phenomenon of film misreading will continue to exist.

\section{The Ultimate Goal of Orientalism - Cultural Hegemony}

The West uses its own discourse system to construct subordinate to the East, serving its own cultural colonial strategy and cultural hegemonism. With the use of Foucault's power discourse system, it is explained that right is the essence of orientalism and gradually evolves into a cultural hegemony.

In the construction of oriental discourse, the West, in addition to establishing the "other" mirror to help the modern Western to complete self-identity, the Western also ideologically defense about colonial expansion carrying out in China [5]. With the far-reaching influence of Orientalism, they practice cultural hegemony and establish their own cultural imperialism. In 1993, Safid deepened and extended the connotation of Orientalism, and further explained the intention of cultural hegemony in the article "Culture and imperialism". From "Orientalism" to "Orientalism" to "culture and imperialism", Saide systemized the construction of the theory of the Western unconsciousness to the East. Orientalism was a means of manipulating ideology. The ultimate goal of the construction of culture was the cultural empire, cultural hegemony became the core concept of postcolonial theory. "In our time, direct control has come to an end. We will see that imperialism continues to exist in the general culture, such as specific political, ideological, economic and social activities, and in the general cultural sphere," he said. " [1] and cultural hegemony give them lasting endurance. That is to say that the building of the cultural empire and cultural hegemony has become the West invase in the political, economic, after another global. In explaining the concept of cultural hegemony, Gramsci 
also emphasizes that cultural hegemony occupies leadership in ideology and uses cultural forms to dominate social life, so that the rulers succumb to the rulers in the conception of consciousness.

The most frightening thing about Orientalism and cultural hegemony is the East succumbed to the idea of orientalism which is built in the West. "Self-orientalization" has become a common phenomenon of Chinese cinema, as an oriental, to participate in its own orientalization, that is, oriental orientalism as a reference and starting point, can be expressed with words. This kind of self-oriental evolution meets the needs of Western cultural hegemony and become a boost.

\section{References}

[1] Qi Yawu Ding Saide: "Culture and Imperialism" [M]. Li Kun translation. Beijing: life, reading, new knowledge of Sanlian bookstore, 2003 edition.

[2] Colin Hoskins, R. Mirus: "Reasons for the U.S. Dominance of the International Trade in Television Program" [J]. "Media Culture Society", 1988 (4); 499-515.

[3] Qi Ya Wudin Sa Yi De. Orientalism [M]. Ma Xuefeng, Su Min translation. Jilin: Jilin People's Publishing House, 2005: 87

[4] Qi Yawu Ding Said. Oriental school. Wang Yu root translation. Beijing: life · reading · new knowledge Sanlian bookstore, 1999: 9

[5] Wan Xuefei. Said's criticism of orientalism and the construction of Chinese culture conscious [J]. Seeking, 2013,06: 103-105.

[6] Clark,Paul. Culture and Politics since 1949.Chinese Cinema[J].1987.

[7] Zhang Liangping, Zhang Wanfang. Orientalism under the perspective of Western movies and hidden perspective [J]. Film review. 2016 (10)

[8] Mou Juan. Philosophy and Social Sciences Edition Study on the Image of Hollywood in the New Century. Journal of Sichuan Normal University. 2015. 